\title{
FAKTOR-FAKTOR PEMBENTUK MOTIVASI INTRINSIK PEKERJA PADA USAHA RESORT \& SPA XYZ DI MANADO
}

\author{
Yustinus Yuniarto'), Elisia Theresia Sonia Moningka ${ }^{2)}$ \\ ${ }^{1,2}$ Manajemen, Universitas Bunda Mulia \\ Diterima 7 Agustus 2020 / Disetujui 31 Agustus 2020
}

\begin{abstract}
Business in the Resort \& Spa business sector is growing rapidly. This increase in business in the hospitality sector reflects the demand for both local and out-of-town visitors. Visitor satisfaction is an important aspect of this service industry. Several studies also focus on the relationship between satisfaction and the behavior of workers in an accommodation. This is important because service delivery according to quality standards is also determined by the performance of the workers in it. This study aims to analyse the factors that influence Intrinsic Motivation. The research subjects in this study were the XYZ company in Manado which was engaged in Resort \& Spa services and the objects in this study were 92 employees who worked at the company. This study uses Partial Least Square (PLS) with SMART PLS 3.0. Intrinsic Motivation variable is not influenced by employee expectations, then this study explains that employee expectations are influenced by work boredom. Furthermore, Intrinsic Motivation is influenced by Work Boredom.
\end{abstract}

Keywords: Intrinsic Motivation, Expectations, Work Boredom

\begin{abstract}
ABSTRAK
Usaha pada sektor usaha Resort \& Spa berkembang pesat. Pertambahan usaha di bidang hospitality ini mencerminkan adanya permintaan baik dari pengunjung baik lokal maupun yang berasal dari luar kota. Kepuasan pengunjung menjadi hal penting dari bidang industri jasa ini. Beberapa penelitian juga fokus mengenai keterkaitan kepuasan dengan perilaku pekerja yang ada di suatu tempat akomodasi penginapan. Hal ini menjadi penting karena penyampaian layanan yang sesuai standar kualitas juga ditentukan dari performa pekerja yang ada di dalamnya. Penelitian ini bertujuan untuk menganalisis faktor-faktor yang memengaruhi Motivasi Intrinsik. Subjek penelitian pada penelitian ini adalah perusahaan XYZ di Manado yang bergerak di bidang jasa Resort \& Spa dan objek pada penelitian ini adalah karyawan yang bekerja di perusahaan tersebut yaitu sebanyak 92 orang. Penelitian ini menggunakan Partial Least Square (PLS) dengan SMART PLS 3.0. Variabel Motivasi Intrinsik tidak dipengaruhi Ekspektasi Karyawan, kemudian penelitian ini menjelaskan bahwa Ekspektasi Karyawan dipengaruhi Kebosanan Bekerja. Selanjutnya Motivasi Intrinsik dipengaruhi Kebosanan Bekerja. Kemudian.
\end{abstract}

Kata Kunci: Motivasi Intrinsik, Ekspektasi, Kebosanan Bekerja

Corresponding author: yyuniarto@bundamulia.ac.id 


\section{PENDAHULUAN}

Persaingan usaha pada sektor usaha Resort \& Spa di Sulawesi Utara berkembang pesat seiring dengan munculnya usaha Resort \& Spa di berbagai titik di Sulawesi Utara. Pertambahan usaha di bidang hospitality ini mencerminkan adanya permintaan baik dari pengunjung baik lokal maupun yang berasal dari luar kota. Kepuasan pengunjung menjadi hal penting dari bidang industri jasa ini. Pengalaman dan rekomendasi dari orang lain dapat membentuk sekaligus menambah nilai jual suatu usaha Resort \& Spa yang ada. Berdasarkan situs layanan tiket perjalanan dan akomodasi Traveloka paling tidak terdapat 10 tempat dive resort terbaik di Sulawesi Utara (Traveloka, 2020). Begitu juga dengan situs perjalanan Tripadvisor yang juga menampilkan beberapa resort \& spa berdasarkan traveller ranked (Tripadvisor, 2020).

Tabel 1. Resort \& Spa Pilihan di Sulawesi Utara

\begin{tabular}{cll}
\hline Urutan & Tinjauan Traveloka & Tinjauan Tripadvisor \\
\hline 1 & Siladen Resort \& Spa di Pulau Siladen & Bunaken Oasis Dive Resort \& Spa \\
2 & Bunaken Oasis Dive Resort \& Spa Bunaken & Siladen Resort \& Spa \\
3 & Lembeh Resort & Raja Laut Dive Resort \\
4 & Gangga Island \& Spa & Froggies Divers Bunaken \\
5 & Manado Nusantara Diving Resort & Aryaduta Manado \\
6 & Bunaken Sea Garden Resort & Novotel Manado Golf Resort \& \\
& & Convention Centre \\
7 & Bastianos Bunaken Resort & Bunaken Cha Cha Nature Resort \\
8 & Thalassa Dive Resort & Two Fish Divers Bunaken \\
9 & Panorama Dive Resort & Onong Resort \\
10 & Kuda Laut Boutique Dive Resort & Murex Dive Resort \\
\hline
\end{tabular}
Sumber: Traveloka (2020); Tripadvisor (2020)

intensi $\begin{gathered}\text { Banyak faktor yang membentuk } \\ \text { pemesanan suatu akomodasi }\end{gathered}$ penginapan. Danish, Hafeez, Ali, Shahid, \& Nadeem (2019) menjelaskan bahwa tinjauan positif yang tersedia secara daring, banyaknya tinjauan yang diberikan dan tampilan yang bersifat realistis dari objek yang dilihat dapat membentuk intensi pemesanan. Zhou, Ye, Pearce, \& Wu (2014) menggunakan enam kategori untuk mengakomodir kriteria yang dapat membentuk kepuasan pengunjung. Keenam kategori tersebut yaitu: pengukuran fisik - ruangan, pengaturan fisik - hotel, pengaturan fisik - makanan, value yang didapat pengunjung, lokasi, dan pekerja. Sementara itu Li, Ye, \& Law (2013) menekankan pada hal-hal seperti kenyamanan transportasi, pengaturan makanan dan minuman, dan nilai uang yang dikeluarkan sebagai suatu pengalaman. Aspek-aspek tersebut juga sama dengan penelitian yang dilakukan oleh (Ramanathan, 2012) dimana nilai dari uang yang dikeluarkan menjadi poin penting dalam kepuasan pengunjung. Selain itu, penelitian ini juga menekankan pada aspek manajemen produk - fisik dan manajemen proses layanan. Yang, Jou, \& Cheng (2011) dalam penelitiannya menekankan pada aspekaspek fasilaitas kolam renang, koneksi internet, harga sewa, sarapan, sikat dan pasta gigi. Selain aspek di dalam penginapan, aspek merek penginapan itu sendiri juga menjadi salah satu pembentuk kepuasan pengunjung seperti ekuitas merek dan brand identification. Kebersihan dan dekorasi juga tidak lepas dari aspek kepuasan pengunjung (Magnini, Crotts, \& Zehrer, 2011). Fu, (2011) menggunakan aspek produk dan layanan yang diberikan 
kepada pengunjunga menjadi faktor pembentuk kepuasan pengunjung.

Beberapa penelitian juga fokus mengenai keterkaitan kepuasan dengan perilaku pekerja yang ada di suatu tempat akomodasi penginapan. Hal ini menjadi penting karena penyampaian layanan yang sesuai standar kualitas juga ditentukan dari performa pekerja yang ada di dalamnya. Yang et al., (2011) dalam penelitiannya menggunakan aspek perilaku staf yang bekerja yang memengaruhi kepuasan pengunjung. Begitu juga dengan Nam, Ekinci, \& Whyatt (2011) yang menggunakan aspek staff behavior untuk mengukur kepuasan pengunjung. Magnini et al., (2011) menggunakan istilah Customer Service yang mana prosesnya sangat bergantung kepada pekerja atau staf yang memberikan layanan yang berkualitas selama pengunjung menginap. Dalam hal kualitas Sanchez-Hernandez, Martinez-Tur, Peiro, \& Moliner, (2010) menekankan pada aspek-aspek seperti functional service quality dan relational service quality. Iklim layanan atau service climate juga dapat menentukan kepuasan pengunjung (Kralj \& Solnet, 2010). Respon yang cepat dan tepat juga menjadi penentu kepuasan pengunjung seperti pada area Front Office ataupun Room Service (Mohsin \& Lockyer, 2010). Layanan yang responsif dari staf dapat memberikan pengalaman positif bagi pengunjung yang dapat membentuk customer value yang baik (Chand, 2010). Selain itu juga, secara spesifik, (Zhou et al., 2014) menggunakan cakupan faktor pekerja atau staf seperti keramahan staf, keterampilan staf dalam berbahasa, dan efisiensi staf dalam menangani suatu masalah. Aspek-aspek yang ada pada staf di suatu penginapan harus diperhatikan agar standar kualitas dapat dipertahankan dan ditingkatkan. Hal ini berkaitan juga dengan motivasi staf yang bekerja dengan optimal. Perputaran karyawan dapat menghambat proses penyampaian layanan yang prima.

Motivasi pada dapat didefinisikan sebagai suatu dorongan untuk melakukan pekerjaan yang membuat pekerja tersebut merasa tertarik dan dapat memuaskan dirinya dalam bekerja (Wu, Wei, Zhang, \& Han, 2011). Di satu sisi, motivasi intrinsik yang terdiri dari pengakuan, kesempatan untuk belajar, dan capaian prestasi dalam bekerja dapat membentuk motivasi yang lebih tinggi bagi pekerja (Jayawardena \& Jayawardena, 2020). Hal ini juga menjelaskan bahwa motivasi intrinsik yang disertai dengan keterampilan pekerja dapat membentuk hasil yang lebih berharga atau berharga bagi karyawan (Boxall, Hutchison, \& Wassenaar, 2014). Dalam berbagai literatur, komitmen pekerja dalam suatu organisasi dapat dipengaruhi oleh beberapa faktor. Pekerja yang merasa ekspektasinya tidak terpenuhi akan cenderung mencoba tantangan baru sebagai bagian dari bentuk motivasi intrinsik (Gkorezis \& Kastritsi, 2017). Karyawan yang telah memiliki pengalaman bekerja memiliki ekspektasi yang berbeda dimana tingkat kompetensi yang dimiliki harus disesuaikan dengan hasil evaluasi dari organisasi karena peniliaiaan tertentu memengaruhi motivasi intrinsik sebagai bagian dari aspek psikologis karyawan tersebut (Minh-Duc \& Huu-Lam, 2019). Pengalaman bekerja dapat membentuk motivasi intrinsik pekerja ( $\mathrm{Wu}$ et al., 2011). Ekspektasi karyawan ditentukan dari dukungan dari lingkungan pekerjaan. Perlakukan yang diterima oleh pekerja dalam melakukan pekerjaan dapat meciptakan bentuk-bentuk motivasi intrinsik tertentu. Gaya kepemimpinan atasan pada hal ini juga dapat berkaitan erat. Hal ini juga dijelaskan oleh Mikkelsen, Andersen, \& Jacobsen (2015) dimana perlakuan yang "keras" kepada pekerja hanya membentuk motivasi yang rendah.

Motivasi intrinsik pekerja dipengaruhi oleh kebosanan bekerja karyawan itu sendiri (Gkorezis \& Kastritsi, 2017). Kebosanan dalam konteks bekerja memiliki ragam definisi (Mael \& Jex, 2015). Rasa bosan dalam bekerja dapat mengindikasikan ketidakberesan dan dapat menjadi pemicu untuk mencari pengalaman baru di tempat lain (Harasymchuk \& Fehr, 2010). Karyawan yang merasa bosan 
yang berkepanjangan dalam bekerja dapat membentuk peningkatan sikap yang negatif dalam bekerja sekaligus menurunkan motivasi intrinsik karyawan tersebut (Hooff \& Hooft, 2017). Pekerjaan yang menarik akan dilakukan dengan motivasi intrinsik yang tinggi oleh para pekerja namun sebaliknya pekerjaan yang tidak menarik akan membuat rendahnya motivasi pekerja dalam melakukan pekerjaan (Shin \& Grant, 2019). Pelanggan yang puas dapat membuat efektivitas positif karyawan meningkat. Hal ini dikarenakan adanya hasil yang baik (posisif) dari layanan yang diberikan karyawan kepada pelanggan sehingga membentuk emosional positif, antusias, dan aktif bagi karyawan (Minh-Duc \& Huu-Lam, 2019). Dari hasil ini karyawan akan tetap bersemangat dan memiliki motivasi dalam melakukan pekerjaan sehingga bentuk kebosanan tidak tercipta. Berdasarkan paparan yang ditelah dijelaskan di atas maka hipotesis pada penelitian ini sebagai berikut:

Hipotesis 1: Ekspektasi karyawan berpengaruh terhadap motivasi intrinsik

Hipotesis 2: Ekspektasi karyawan berpengaruh terhadap kebosanan bekerja

Hipotesis 3: Kebosanan bekerja berpengaruh terhadap motivasi intrinsik

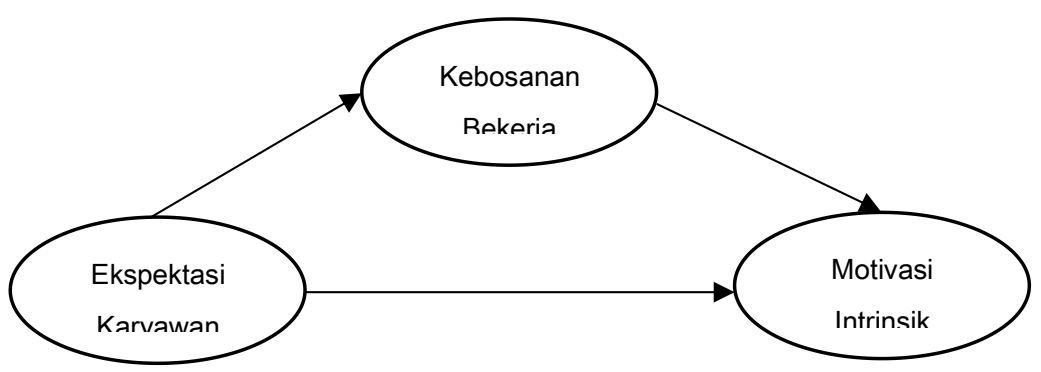

Gambar 1. Model Penelitian

Sumber: Gkorezis \& Kastritsi (2017)

\section{METODE PENELITIAN}

Subjek penelitian pada penelitian ini adalah perusahaan XYZ di Manado yang bergerak di bidang jasa resort \& spa dan objek pada penelitian ini adalah karyawan yang bekerja di perusahaan tersebut. Jenis penelitian kuantitatif ini menggunakan sampel jenuh dimana keseluruhan karyawan dilibatkan menjadi responden yaitu sebanyak 92 orang. Pada penelitian ini, peneliti menggunakan
Partial Least Square (PLS) dengan SMART PLS 3.0.

\section{HASIL DAN PEMBAHASAN}

Penelitian ini terdiri dari 70 orang laki-laki atau sebesar $76,09 \%$ dan perempuan sebanyak 22 orang responden perempuan atau sebesar 23,91\%. Uji validitas dilakukan dengan melihat hasi Outer Loading dan Average Variance Extracted (AVE). 
Tabel 2. Hasil Outer Loading

\begin{tabular}{lccc}
\hline Variabel & Item & Hasil & Keterangan \\
\hline Ekspektasi & EK1 & 0,989 & Valid \\
Karyawan & EK2 & 0,989 & Valid \\
\hline & KB1 & 0,961 & Valid \\
Kebosanan & KB2 & 0,942 & Valid \\
Bekerja & KB3 & 0,959 & Valid \\
& KB4 & 0,965 & Valid \\
& KB5 & 0,894 & Valid \\
\hline & MI1 & 0,845 & Valid \\
Motivasi & MI2 & 0,734 & Valid \\
Intrinsik & MI3 & 0,820 & Valid \\
& MI4 & 0,716 & Valid \\
& MI5 & 0,863 & Valid \\
\hline
\end{tabular}

Sumber: Peneliti diolah dengan SMART PLS 3.0; $\mathrm{n}=92$

Berdasarkan tabel 2 di atas dapat dijelaskan bahwa semua item sudah dinyatakan valid dimana pada data yang diolah nilai terbesar pada indicator EK1 dan EK2 yaitu 0,989 dan yang terkecil indikator MI4 yaitu 0,716. Pada tabel 3 menunjukkan bahwa penelitian ini dinyatakan valid karena semua variabel dalam penelitian ini memiliki nilai di atas 0,50 .

Tabel 3. Hasil Outer Loading

\begin{tabular}{lcc}
\hline Variabel & Hasil & Keterangan \\
\hline Ekspektasi Karyawan & 0,979 & Valid \\
Kebosanan Bekerja & 0,892 & Valid \\
Motivasi Intrinsik & 0,636 & Valid \\
\hline
\end{tabular}

Sumber: Peneliti diolah dengan SMART PLS 3.0; $\mathrm{n}=92$

Berdasarkan hasil uji reliabilitas dan composite reliability (tabel 4), maka dapat disimpulkan maka semua data tersebut dapat diandalkan karena masing - masing variabel memiliki nilai lebih dari 0,70. Dengan tingkat reliabilitas tertinggi terdapat di varibel Ekspektasi Karyawan dengan nilai 0,938.

Tabel 4. Hasil Outer Loading

\begin{tabular}{lccc}
\hline Variabel & Cronbach's Alpha & Composite Reliability & Keterangan \\
\hline Ekspektasi Karyawan & 0.978 & 0.989 & Reliabel \\
Kebosanan Bekerja & 0.970 & 0.976 & Reliabel \\
Motivasi Intrinsik & 0.856 & 0.897 & Reliabel \\
\hline
\end{tabular}

Sumber: Peneliti diolah dengan SMART PLS 3.0; $\mathrm{n}=92$

Berdasarkan hasil uji koefisien korelasi (tabel 5), dapat dijelaskan bahwa korelasi antara Ekspektasi Karyawan dan
Kebosanan Bekerja memiliki nilai paling tinggi yaitu 0,698 . Hal ini memberikan makna bahwa Kebosanan Bekerja yang di pengaruhi 
oleh Ekspektasi Karyawan dapat menciptakan hubungan yang kuat dengan presentase $69,80 \%$. Selanjutnya korelasi terendah yaitu Motivasi Intrinsik dan Ekspektasi Karyawan dengan nilai 0,542. Hal ini memberikan makna bahwa Ekspektasi Karyawan dan Motivasi Intrinsik dapat menciptakan hubungan yang kuat sebesar $54,20 \%$.

Tabel 5. Korelasi Antar Variabel

\begin{tabular}{lccc}
\hline Variabel & Ekspektasi Karyawan & Kebosanan Bekerja & Motivasi Intrinsik \\
\hline Ekspektasi Karyawan & 1 & 0.698 & 0.542 \\
Kebosanan Bekerja & 0.698 & 1 & 0.677 \\
Motivasi Intrinsik & 0.542 & 0.677 & 1 \\
\hline
\end{tabular}

Sumber: Peneliti diolah dengan SMART PLS 3.0; $\mathrm{n}=92$

Berdasarkan tabel 6 variabel Kebosanan Bekerja menunjukan nilai sebesar 0,487 yang artinya Kebosanan Bekerja dipengaruhi oleh Ekspektasi Karyawan sebesar $48,70 \%$. Selanjutnya Motivasi Intrinsik menunjukan nilai 0,468 yang artinya variabel Motivasi Intrinsik dipengaruhi oleh Ekspektasi Karyawan dan Kebosanan Bekerja sebesar $46,80 \%$.

Tabel 6. Hasil $R$ Square

\begin{tabular}{lc}
\hline Variabel & Ekspektasi Karyawan \\
\hline Kebosanan Bekerja & 0,487 \\
Motivasi Intrinsik & 0,468 \\
\hline Sumber: Peneliti diolah dengan SMART PLS 3.0; $\mathrm{n}=92$
\end{tabular}

Berdasarkan Path Coefficients (Bootstrapping) dapat dijelaskan bahwa $t$ table sebesar $0,940<1,96$ maka Motivasi Intrinsik tidak dipengaruhi Ekspektasi Karyawan dengan nilai $P$ Value adalah 0,348 yang menjelaskan pengaruh Ekspektasi Karyawan dan Motivasi Intrinsik adalah tidak signifikan. Berdasarkan hasil ini dapat dijelaskan bahwa Hipotesis 1 ditolak. Hasil penelitian ini juga menolak penelitian yang dilakukan oleh (Gkorezis \& Kastritsi, 2017). Berdasarkan $t$ table sebesar 10,233 > 1,96 maka Ekspektasi Karyawan dipengaruhi Kebosanan Bekerja dengan nilai $P$ Value adalah 0,000 yang menjelaskan pengaruh Ekspektasi Karyawan dan Kebosanan Bekerja adalah signifikan. Berdasarkan hasil ini dapat dijelaskan bahwa Hipotesis 2 diterima. Hasil penelitian ini menolak penelitian yang dilakukan oleh (Gkorezis \& Kastritsi, 2017). Berdasarkan $t$ table sebesar 3,949>1,96 maka Motivasi Intrinsik dipengaruhi Kebosanan Bekerja dengan nilai $P$ Value adalah 0,000 yang menjelaskan pengaruh Kebosanan Bekerja dan Motivasi Intrinsik adalah signifikan. Berdasarkan hasil ini dapat dijelaskan bahwa Hipotesis 3 diterima. Hasil penelitian ini menolak penelitian yang dilakukan oleh (Gkorezis \& Kastritsi, 2017). 
Tabel 6. Hasil Path Coefficients

\begin{tabular}{lcc}
\hline \multicolumn{1}{c}{ Path } & T Statistics $(\boldsymbol{O O} / \boldsymbol{S T D E} \boldsymbol{V})$ & P Values \\
\hline Ekspektasi Karyawan $\rightarrow$ Motivasi Intrinsik & 0.940 & 0.348 \\
Ekspektasi Karyawan $\rightarrow$ Kebosanan Bekerja & 10.233 & 0.000 \\
Kebosanan Bekerja $\rightarrow$ Motivasi Intrinsik & 3.949 & 0.000 \\
\hline
\end{tabular}

Sumber: Peneliti diolah dengan SMART PLS 3.0; $\mathrm{n}=92$

\section{SIMPULAN DAN SARAN}

Berdasarkan hasil dan pembahasan di atas, maka simpulan penelitian ini dapat dijelaskan sebagai berikut:

1. Variabel Motivasi Intrinsik tidak dipengaruhi Ekspektasi Karyawan.

2. Variable Ekspektasi Karyawan dipengaruhi Kebosanan Bekerja.

3. Variable Motivasi Intrinsik dipengaruhi Kebosanan Bekerja.

Selanjutnya saran pada penelitian ini yaitu adanya program untuk reward atau pengembangan diri yang jelas agar ekspektasi karyawan dengan jelas diketahui. Programprogram selingan yang menarik seperti gathering, outbond, ataupun makan bersama sesekali perlu dilakukan untuk mengurangi kejenuhan dalam bekerja. Bagi penelitian selanjutnya penambahan variabel seperti pengalaman bekerja karyawan, work-life balance, ataupun komitmen organisasi dapat diharapkan dapat memperkaya hasil kajian mengenai faktor-faktor yang membentuk motivasi intrinsik karyawan.

\section{DAFTAR PUSTAKA}

Boxall, P., Hutchison, A., \& Wassenaar, B. (2014). How do high-involvement work processes influence employee outcomes? An examination of the mediating roles of skill utilisation and intrinsic motivation. The International Journal of Human Resource Management, 26(13), 1-16.

Chand, M. (2010). The impact of HRM practices on service quality, customer satisfaction and performance in the Indian hotel industry. International Journal of Human Resource
Management, 21(4), 551-566.

Danish, R. Q., Hafeez, S., Ali, H. F., Shahid, M. R., \& Nadeem, K. (2019). Impact of Online Consumer Reviews on Hotel Booking Intentions: The Case of Pakistan. European Scientific Journal, 15(7), 144159.

Fu, H. (2011). An exploration of the role of product and service elements affecting customer satisfaction in UK hotels. Proceedings of the Fifth International Symposium on Green Hospitality and Tourism Management, 504-519. Marietta, GA: American Scholars Press.

Gkorezis, P., \& Kastritsi, A. (2017). Employee expectations and intrinsic motivation: work- related boredom as a mediator. Employee Relations, 39(1), 100-111.

Harasymchuk, C., \& Fehr, B. (2010). A script analysis of relational boredom: Causes, feelings, and coping strategies. Journal of Social and Clinical Psychology, 29(9), 988-1019.

Hooff, M. L. M. van, \& Hooft, E. A. J. van. (2017). Boredom at work: towards a dynamic spillover model of need satisfaction, work motivation, and workrelated boredom. European Journal of Work and Organizational Psychology, 26(1), 133-148.

Jayawardena, N. S., \& Jayawardena, D. (2020). The impact of extrinsic and intrinsic rewarding system on employee motivation in the context of Sri Lankan apparel sector. International Journal of Business Excellence, 20(1), 51-69. 
Kralj, A., \& Solnet, D. (2010). Service climate and customer satisfaction in a casino hotel: An exploratory case study. International Journal of Hospitality Management, 29(4), 711-719.

Li, H., Ye, Q., \& Law, R. (2013). Determinants of Customer Satisfaction in the Hotel Industry: An Application of Online Review Analysis. Asia Pacific Journal of Tourism Research, 18(7), 784-802.

Mael, F., \& Jex, S. (2015). Workplace boredom an integrative model of traditional and contemporary approaches. Group \& Organization Management, 40(2), 131-159.

Magnini, V. ., Crotts, J. ., \& Zehrer, A. (2011). Understanding customer delight: An application of travel blog analysis. Journal of Travel Research, 50(5), 535545.

Mikkelsen, M. F., Andersen, L. B., \& Jacobsen, C. B. (2015). Managing Employee Motivation: Exploring the Connections Between Managers' Enforcement Actions, Employee Perceptions, and Employee Intrinsic Motivation. International Public Management Journal, 183-205.

Minh-Duc, L., \& Huu-Lam, N. (2019). Transformational leadership, customer citizenship behavior, employee intrinsic motivation, and employee creativity. Journal of Asian Business and Economic Studies, 26(2), 286-300.

Mohsin, A., \& Lockyer, T. (2010). Customer perceptions of service quality in luxury hotels in New Delhi, India: an exploratory study. International Journal of Contemporary Hospitality Management, 22(2-3), 160-173.

Nam, J., Ekinci, Y., \& Whyatt, G. (2011). Brand equity, brand loyalty and consumer satisfaction. Annals of Tourism Research, 38(3), 1009-1030.

Ramanathan, R. (2012). An exploratory study of marketing, physical and people related performance criteria in hotels. International Journal of Contemporary Hospitality Management, 24(1), 44-61.

Sanchez-Hernandez, R. ., Martinez-Tur, V., Peiro, J. ., \& Moliner, C. (2010). Linking functional and relational service quality to customer satisfaction and loyalty: Differences between men and women. Reports, Psychological, 106(2), 598-61.

Shin, J., \& Grant, A. M. (2019). Bored by Interest: Intrinsic Motivation in One Task Can Reduce Performance on Other Tasks. Academy of Management Journal, 1-45.

Traveloka. (2020). Dive Resort Terbaik di Sulawesi Utara. Retrieved September 25, 2020, from Traveloka website: https://www.traveloka.com/id-id/hotelguides/dive-resort-north-sulawesi

Tripadvisor. (2020). Manado Resorts. Retrieved September 25, 2020, from Tripadvidor website: https://www.tripadvisor.com/Hotelsg297721-zff8-

Manado North Sulawesi SulawesiHotels.html

Wu, L., Wei, L.-Q., Zhang, Y., \& Han, T. (2011). Employee Experienced HPWPs and Job Performance: Roles of PersonJob Fit and Intrinsic Motivation. Frontiers of Business Research in China, 5(3), 344-363.

Yang, C. C., Jou, Y. T., \& Cheng, L. . (2011). Using integrated quality assessment for hotel service quality. Quality \& Quantity, 45(2), 349-364.

Zhou, L., Ye, S., Pearce, P. L., \& Wu, M.-Y. (2014). Refreshing hotel satisfaction studies by reconfiguring customerreview data. International Journal of Hospitality Management, 38, 1-10. 